\title{
Preference, Perception And Predictors Of Herbal Medicine Use Among Malay Women In Malaysia
}

This article was published in the following Dove Press journal:

Patient Preference and Adherence

\author{
Tengk Azlan Shah Tengku \\ Mohamad ${ }^{1,2}$ \\ Farida Islahudin' \\ Malina Jasamai' \\ Jamia Azdina Jamal' \\ 'Faculty of Pharmacy, Universiti \\ Kebangsaan Malaysia, Kuala Lumpur \\ 50300, Malaysia; ${ }^{2}$ Faculty of Pharmacy, \\ Universiti Kuala Lumpur Royal College of \\ Medicine Perak, Ipoh 30450, Perak, \\ Malaysia
}

Background: Preference for herbal use is increasing worldwide. This is especially true for Malay women in Malaysia that is steeped in traditional and cultural values and surrounded by diverse flora. However, concerns arise with the use of herbs due to the lack of monitoring, scientific evidence and risk of adverse effects. As such identifying potential herbal users is vital to ensure appropriate management is optimised.

Objective: This study derives insights on preferred herbs, perception and predictors of herbal use for health among Malay women in Malaysia.

Methods: This was a cross-sectional survey, comprising of Malay women, performed in all fourteen states in Malaysia. Respondents were assessed for demographic characteristic, current use of herbal medicine, their preferred herbal medicine and perception of herbal use. Predictors of herbal use were then determined using a multivariate logistic regression model.

Results: A total of 1067 respondents were included in the study of which $592(55.5 \%)$ admitted to using herbs for health. In general, raw herbs were the most preferred herbal remedies used $(n=407,69.5 \%)$. A significantly higher number of respondents perceived that herbal remedies would not cause any problems to women's overall health $(n=725,67.9 \%)$ $(\chi 2=137.5, \mathrm{df}(1), \mathrm{p}<0.001)$, although a large majority agreed that not all remedies were safe for pregnant women $(\mathrm{n}=979,91.8 \%)(\chi 2=744.03, \mathrm{df}(1), \mathrm{p}<0.001)$. Among predictors of herbal use were marital status and income $(\chi 2=203.98, \operatorname{df}(795) \mathrm{p}<0.001)$. Those that were married were 3.9 times more likely to use herbs than unmarried women $(\mathrm{p}<0.001)$. Having an income of $<$ RM 3000 or USD 729 increased the odds of using herbs among women by 6.2 times compared to their counterparts $(\mathrm{p}<0.001)$.

Conclusion: The current findings provide an insight into specific groups, information and health initiatives that can be targeted to strengthen herbal use monitoring among Malay women.

Keywords: health, herb, Malay, preference, perception, predictor, women

\section{Introduction}

Approximately $70 \%$ of the world's population from developing countries prefer herbal medicinal products as a primary source of healthcare. ${ }^{1,2}$ Herbal medicinal products are medicinal products that consist of a plant, or a concoction of various plants, often used due to its believed beneficial effect, ${ }^{3,4}$ and are a popular source for disease management and prevention. Within the past decade, there has been a tremendous surge in herbal therapies, as herbs are easily assessable directly from traditional healers or commercially available in many countries, ${ }^{2}$ including in Malaysia.

Preference towards herbal use is common within the Malay women community ${ }^{5}$ and is at higher odds compared to other ethnicities in Malaysia. ${ }^{6}$ The use of herbs for medicinal purposes is largely based on theory, beliefs, and experiences that are
Correspondence: Farida Islahudin Faculty of Pharmacy, Universiti Kebangsaan Malaysia, Jalan Raja Abdu Aziz, Kuala Lumpur 50300, Malaysia Email faridaislahudin@yahoo.com 
indigenous to specific cultures. ${ }^{7,8}$ Herbal remedies are usually preferred over conventional medicine as it is perceived to be important for reasons of health and wellbeing, including being beneficial during pregnancy. ${ }^{9}$ The most common herbs that are used among Malay women are raw herbs and commercialized herbal products. ${ }^{10}$ For example, herbs such as Croton caudatus, coconut oil and Cymbopogon citratus are among a few frequently used during pregnancy and in postnatal care among the Malay community. ${ }^{11,12}$ However, there are significant variations in the popularity of herbs used by Malay women depending on location, ${ }^{11,12}$ and despite the variety of herbs available, evidence for the safety and efficacy is still limited. ${ }^{13}$ Such practice modalities should raise concerns among healthcare professionals and consumers.

The common use of herbs among the Malay community is due to the perception that herbal products do not contain harmful chemicals and are free of side effects. ${ }^{10,14}$ The perception that herbs are natural sources and are therefore safer is also a common misconception observed among herbal users. ${ }^{15,17}$ Women are also largely affected by recommendations by family and friends, and are known to self-prescribe herbal remedies for treatment or prevention of ailments. ${ }^{15,16}$ Although allopathic treatments and technologies are abundant, the inability to recognize or feel positive changes may also influence them to try herbal remedies. ${ }^{15,16}$ Thus, with the steady increase of herbal medicinal products, concerns surrounding their safety must be recognized.

The factors that affect herbal use among women may differ from one population to another. It is believed that the popular use of herbs in developing countries is due to the accessibility and availability of the product. ${ }^{2,7}$ Housewives and those with a lower income were the most frequent users of herbs in the local population. ${ }^{7,8}$ Recent work in Malaysia demonstrated that those with a more positive attitude and stronger belief towards herbal use had a higher tendency to use herbal medicine. ${ }^{1}$ Given that herbal medicines are often portrayed as being harmless, the public may be at an additional risk, which underlies the need to further understand the reasons behind herbal medicine use.

Non-disclosure of herbal use is a common scenario among women. ${ }^{16}$ The utilization and self-prescribing of herbs for medicinal purposes among women is of particular concern due to the risk of potential safety issues linked, but not limited to, pregnancy, breast-feeding and other maternity complications. In view of this, healthcare professionals must address these issues and furnish appropriate programs to ensure both the public and patients are well-informed. At present there is limited work addressing current predictors of herbal use among Malay women, that may potentially be used to screen high-risk users and develop appropriate educational programs. To address these concerns, an insight into the use of current herbs among Malay women may aid in identifying potential users and optimising management of herbal remedies. The aim of this work is therefore to identify preference, perception and predictors of herbal use among Malay women within the local population.

\section{Methods \\ Study Design}

The study was a cross-sectional study among women in Malaysia. Those that were included were Malay adults aged 18 years old, regardless of their health status. Respondents were included conveniently through selfadministered questionnaires, which were distributed by hand, as well as online via email. Questionnaires were distributed by hand in public places such as malls, bus stops and train stations. Incomplete questionnaires were excluded from the study. A total of 384 respondents ${ }^{18}$ was required based on an approximate population of 11290 000 adult women in Malaysia. ${ }^{19}$ However, a total of 1200 respondents were targeted to increase the power of the study and to allow for subgroup analysis.

From a total of 1200 questionnaires, 817 were distributed by hand and 383 were sent via email, of which 1067 questionnaires were completed (720 by hand and 347 online). Incomplete questionnaires accounted for 133 (11.1\%) of the sample population. The survey response rate, defined as the number of completed questionnaires was $88.9 \%$ (Figure 1).

\section{Ethical Approval}

The study has been approved by the appropriate institutional and/or national research ethics committee and has been performed in accordance with the ethical standards as laid down in the 1964 Declaration of Helsinki and its later amendments or comparable ethical standards. Ethical approval was obtained from the Research Ethics Committee (Human), under the Medical and Innovation Research Secretariat, Universiti Kebangsaan Malaysia Medical Center (JEP-2018-522). All patients were included with written informed consent. 
Questionnaires distributed among the public $(n=1200)$

\begin{tabular}{lccc}
\hline States & By hand, $\mathbf{n}$ & Email, $\mathbf{n}$ & Total, $\mathbf{n}$ \\
\hline Johor & 61 & 33 & 94 \\
Kedah & 44 & 37 & 81 \\
Kelantan & 28 & 13 & 41 \\
Melaka & 35 & 11 & 46 \\
Negeri Sembilan & 38 & 18 & 56 \\
Pahang & 90 & 23 & 113 \\
Perak & 36 & 74 & 110 \\
Perlis & 45 & 6 & 51 \\
Pulau Pinang & 32 & 10 & 42 \\
Sabah & 101 & 24 & 125 \\
Sarawak & 123 & 7 & 130 \\
Selangor & 79 & 86 & 165 \\
Terengganu & 51 & 13 & 64 \\
Wilayah Persekutuan & 54 & 28 & 82 \\
\hline Total & 817 & 383 & 1200 \\
\hline
\end{tabular}

Exclusion of incomplete questionnaires $(n=133)$

\begin{tabular}{lccc}
\hline States & By hand, n & Email, n & Total, $\mathbf{n}$ \\
\hline Johor & 10 & 2 & 12 \\
Kedah & 4 & 2 & 6 \\
Kelantan & 6 & 2 & 8 \\
Melaka & 11 & 1 & 12 \\
Negeri Sembilan & 4 & 2 & 6 \\
Pahang & 10 & 6 & 16 \\
Perak & 8 & 4 & 12 \\
Perlis & 7 & 2 & 9 \\
Pulau Pinang & 1 & 1 & 2 \\
Sabah & 13 & 4 & 17 \\
Sarawak & 10 & 5 & 15 \\
Selangor & 3 & 1 & 4 \\
Terengganu & 8 & 3 & 11 \\
Wilayah Persekutuan & 2 & 1 & 3 \\
\hline Total & 97 & 36 & 133 \\
\hline
\end{tabular}

Completed questionnaires included in the study $(\mathrm{n}=1067)$

\begin{tabular}{lccc}
\hline States & By hand, n & Email, n & Total \\
\hline Johor & 51 & 31 & 82 \\
Kedah & 40 & 35 & 75 \\
Kelantan & 22 & 11 & 33 \\
Melaka & 24 & 10 & 34 \\
Negeri Sembilan & 34 & 16 & 50 \\
Pahang & 80 & 17 & 97 \\
Perak & 28 & 70 & 98 \\
Perlis & 38 & 4 & 42 \\
Pulau Pinang & 31 & 9 & 40 \\
Sabah & 88 & 20 & 108 \\
Sarawak & 113 & 2 & 115 \\
Selangor & 76 & 85 & 161 \\
Terengganu & 43 & 10 & 53 \\
Wilayah Persekutuan & 52 & 27 & 79 \\
\hline Total & 720 & 347 & 1067 \\
\hline & & &
\end{tabular}

Figure I Flowchart of survey respondent's selection. 


\section{Data Collection}

The respondents answered a self-administered questionnaire, face-to-face or online. ${ }^{20}$ The questionnaire assessed demographic variables, current use of herbs for health, and perception on the use of herbs for health. ${ }^{7,15,21}$ Face and content validation of the questionnaire of both the face-toface and online version was undertaken by a panel of five adult women respondents. Feedback was gathered to improve the questionnaire presentation, clarity, and congruency in meaning. Modifications were made and a pilot test of both face-to-face and the online version was performed among 20 respondents. The final version of the questionnaire was personally distributed by the researcher and collected once completed on the same day, or sent online via Facebook or email to potential respondents.

\section{Demographics}

Demographic characteristics collected were age, state, marital status, level of education, employment status, average monthly income and health status. Gender and ethnicity were also included to exclude forms that were incorrectly filled by males and non-Malay ethnicities.

\section{Herbal Use Among Women}

The definition of herbal use for health was "any products originating from plants and used to preserve or recover health", as described by the National Institutes of Health (2011). ${ }^{22}$ Herbal use was determined based on the statement: Are you currently using herbs or herbal products for health issues? Those that admitted to the use of herbs were then asked further questions such as; monthly expenditure of herbal use, what herbs were used, form of herbs used, type of herbs (raw or commercialized herbs) and what herbs were used for (skin problems, general health, chronic illness, acute illness, specific women's problems, others). Respondents were also asked where they obtained their herbs (the jungle/around the village, traditional practitioner, agent/distributor, internet, doctor/pharmacist, family/friend, herbal shop, shop/supermarket, own herbs, others). Reasons for herbal use were also determined based on six statements; 7,15 easy access of herbal remedy, low cost of herbal remedy, better/faster results compared to conventional medicine, natural taste of herbal drug, health facility is too far, and influence from family or relative or peer. Respondents answered each statement with a "Yes" or "No" response. 7,15,21

\section{Perception Of Herbal Use Among Women}

Perception of herbal use for health was assessed based on previous work. $^{15}$ This was based on six statements which were; herbal remedies are safer than modern drugs, herbal remedies are effective for managing health problems for women, herbal remedies should be used by all women, herbal remedies may cause problems to women's overall health, all herbal remedies can safely be used during pregnancy, and I am satisfied with the effect and outcomes of using herbal medicines. Each statement was followed by a "Yes" or "No" response.

\section{Data Analyses}

Data were analysed using SPSS (version 23.0) (IBM Corp. Armonk, NY, USA). Demographic characteristics, herbal use and perception of herbal use were summarized using descriptive statistics. Students' $t$-tests and Chi-squared tests were used to compare differences in means and categorical data, respectively. A univariate and multivariate logistic regression was used to determine predictors of herbal use among women. Continuous data were categorised based on its median value. ${ }^{23}$ For all analyses, a p-value of $<0.05$ was considered to be statistically significant.

\section{Results}

\section{Demographics}

A total of 1067 respondents from both Peninsular and East Malaysia were included in the study. The average age of the respondents was $36.75 \pm 10.72$ (range 20-70) years, with a mean monthly income of RM $3587 \pm 4542$ or USD $872 \pm 1104$ (range RM 100-60,000 or USD 24-14,592). In general, most of the respondents $(n=815,76.4 \%)$ had tertiary education compared to secondary $(n=250,23.4 \%)$ and primary education $(\mathrm{n}=2,0.2 \%)$. A large majority of the women were married $(\mathrm{n}=760,71.2 \%)$, followed by those that were not married $(\mathrm{n}=286,26.8 \%)$, divorced $(\mathrm{n}=14,1.3 \%)$ and widows $(\mathrm{n}=7$, $0.7 \%$ ). A total of 775 respondents were working (government - $\mathrm{n}=419,39.3 \%$; non-government- $\mathrm{n}=291,27.2 \%$; selfemployed- $\mathrm{n}=65,6.1 \%$ ). The remaining 292 were unemployed (retiree $-\mathrm{n}=7,0.7 \%$; unemployed $-\mathrm{n}=29,2.7 \%$; housewife $\mathrm{n}=194,18.2 \%)$. Of the 1067 respondents, 966 (90.5\%) were healthy whilst $101(9.5 \%)$ were currently receiving treatment.

\section{Herbal Use Among Women}

A total of $592(55.5 \%)$ respondents admitted to using herbs for health. Herbal users were significantly older (37.2 \pm 9.9 years) than those that were not $(36.2 \pm 11.6$ 
years) (Mann Whitney $=128182.5, \operatorname{df}(1065), \mathrm{p}=0.013$ ). Married women were also more likely to use herbs $(n=482,45.2 \%)$ compared to others $(\chi 2=86.36, \operatorname{df}(3)$, $\mathrm{p}<0.001)$. It was also noted that employed respondents $(n=460,43.1 \%)$ were more likely to use herbs, compared to those that were not $(\mathrm{n}=132,12.4 \%)\left(\chi^{2}=17.19, \operatorname{df}(1)\right.$, $\mathrm{p}<0.001)$. When comparing monthly income, herbal users had a lower monthly income (RM $2313 \pm 1200$ or USD 562 \pm 291 ) compared to those that did not use herbs (RM 5602 \pm 6664 or USD $1362 \pm 1620)(t=10.593, \operatorname{df}(789), \mathrm{p}<0.001)$. There was also a significant difference between users and health status, with a higher number of herbal users among healthy women $(\mathrm{n}=519,48.6 \%)$ compared to those receiving treatment $(n=73,6.8 \%)(\chi 2=12.7, \operatorname{df}(1), p<0.001)$. The characteristics of herbal use are as stated in Table 1.

Herbs were mainly used for general health $(n=271$, 43.9\%). Specific women's problems $(n=247,40 \%)$ included postnatal $(\mathrm{n}=212)$, menstrual problems $(\mathrm{n}=21)$, fertility $(n=10)$, endometriosis $(n=3)$ and uterus inflammation $(n=1)$. Among the most popular use of herbs for chronic illness $(n=19,3.1 \%)$ was hypertension $(n=6)$, followed by diabetes $(n=3)$. Whilst the most common use for

Table I Characteristics Of Herbal Use Among Malay Women In Malaysia $(n=592)$

\begin{tabular}{|c|c|c|}
\hline Characteristics & Mean (SD)/n & Range/\% \\
\hline Average RM/USD spent on herbs, mean (SD) (range) & $105.9(84.3) / 24(20.5)$ & $0-600 / 0-145$ \\
\hline $\begin{array}{l}\text { Form of herbs used, } \mathrm{n}(\%) \\
\text { - Raw herbs taken orally } \\
\text { - Capsule/tablet/powder taken orally } \\
\text { - Drink/tea } \\
\text { - External use }\end{array}$ & $\begin{array}{l}268 \\
184 \\
111 \\
48\end{array}$ & $\begin{array}{l}43.9 \\
30.1 \\
18.1 \\
7.9\end{array}$ \\
\hline $\begin{array}{l}\text { Type of herbs, } \mathrm{n}(\%) \\
\text { - Raw herbs } \\
\text { - Commercialised herbs } \\
\text { - Combination of raw and commercialized herbs }\end{array}$ & $\begin{array}{l}407 \\
167 \\
12\end{array}$ & $\begin{array}{l}69.5 \\
28.5 \\
2.0\end{array}$ \\
\hline $\begin{array}{l}\text { Herbs are taken for, } \mathrm{n}(\%) \\
\text { - General health } \\
\text { - Specific women's problems } \\
\text { - Skin problems } \\
\text { - Acute illness } \\
\text { - Chronic illness } \\
\text { - Others, not specified }\end{array}$ & $\begin{array}{l}271 \\
247 \\
52 \\
23 \\
19 \\
4\end{array}$ & $\begin{array}{l}43.9 \\
40.0 \\
8.4 \\
3.7 \\
3.1 \\
0.6\end{array}$ \\
\hline $\begin{array}{l}\text { Herbs are obtained from, } \mathrm{n}(\%) \\
\text { - Traditional practitioner } \\
\text { - Internet } \\
\text { - The jungle/around the village } \\
\text { - Doctor/Pharmacist } \\
\text { - Herbal shop } \\
\text { - Agent/distributor } \\
\text { - Shop/supermarket } \\
\text { - Own herbs } \\
\text { - Family/friend } \\
\text { - Others, not specified }\end{array}$ & $\begin{array}{l}254 \\
146 \\
116 \\
55 \\
30 \\
28 \\
8 \\
7 \\
5 \\
2\end{array}$ & $\begin{array}{l}39.0 \\
22.4 \\
17.8 \\
8.5 \\
4.6 \\
4.3 \\
1.2 \\
1.1 \\
0.8 \\
0.3\end{array}$ \\
\hline $\begin{array}{l}\text { Reasons for herbal use } \\
\text { - Influence from family/relative/peer } \\
\text { - Easy access to herbal remedy } \\
\text { - Natural taste of herbal drug } \\
\text { - Better/faster results compared to conventional medicine } \\
\text { - Low cost of herbal remedy } \\
\text { - Health facility is too far }\end{array}$ & $\begin{array}{l}757 \\
755 \\
636 \\
483 \\
436 \\
241\end{array}$ & $\begin{array}{l}70.9 \\
70.8 \\
59.6 \\
45.3 \\
40.9 \\
22.6\end{array}$ \\
\hline
\end{tabular}


acute illness $(n=23,3.7 \%)$ was for the management of allergies $(\mathrm{n}=12)$.

In general, raw herbs were the most popular herbal remedies used $(n=407,69.5 \%)$. The most common raw herb identified was kacip fatimah or Marantodes pumilum which was used for postnatal care (Table 2). A significant number of respondents used commercialized herbal products that were found abundantly and marketed as herbal (jamu/majun) products. In Malaysia, these products are advertised and sold using agents or distributors. The most common among these were various different brands such as Nona Roguy ${ }^{\circledR}(\mathrm{n}=32$, $5.5 \%)$ and Jamu Ratu Malaya ${ }^{\circledR}(\mathrm{n}=32,5.5 \%)$ products, which were used for postnatal birth care, skin problems and general health. There were various types of Nona Roguy ${ }^{\circledR}$ and Jamu Ratu Malaya ${ }^{\circledR}$ products used. However, the content of these herbal products usually differed from one another and could not be determined.

\section{Perception Of Herbal Use Among Women}

The perception of herbal remedies was assessed (Table 3). A significantly higher number of respondents agreed that herbal remedies would not cause any problems to women's overall health $(\mathrm{n}=725,67.9 \%)(\chi 2=137.5, \mathrm{df}(1), \mathrm{p}<0.001)$ and that they were satisfied with the effects and outcomes of herbal remedies $(\mathrm{n}=657,61.6 \%) \quad(\chi 2=57.2, \mathrm{df}(1)$, $\mathrm{p}<0.001)$. Despite this, a large majority agreed that not

Table 2 Indications Of The Most Common Raw Herb Combinations Used Among Malay Women In Malaysia ( $n=407)$

\begin{tabular}{|c|c|c|c|}
\hline Local Herb Name & Scientific Name & Uses & n (\%) \\
\hline Kacip fatimah & Marantodes pumilum & $\begin{array}{l}\text { Postnatal, general health, fertility, } \\
\text { diabetes }\end{array}$ & $38(9)$ \\
\hline Habatussauda & Nigella sativa & $\begin{array}{l}\text { General health, skin problems, } \\
\text { endometriosis }\end{array}$ & $24(6)$ \\
\hline Manjakani, asam jawa, kunyit & Croton caudatus, Tamarindus indica, Curcuma longa & Postnatal & $14(3)$ \\
\hline Tepayas roots & Carica papaya leaves & $\begin{array}{l}\text { Postnatal, general health, skin } \\
\text { problems, menstrual problems }\end{array}$ & $12(3)$ \\
\hline Manjakani, serapat roots & Croton caudatus, Mapania cuspidate roots & Postnatal & $9(2)$ \\
\hline Sirih rimau & Piper porphyrophyllum & Postnatal & $8(2)$ \\
\hline Kunyit, halia, halia Jawa, misai kucing & $\begin{array}{l}\text { Curcuma longa, Zingiber officinale, Curcuma } \\
\text { zanthorrhiza, Orthosiphon stamineus }\end{array}$ & Postnatal & $7(2)$ \\
\hline Mengkudu leaves, serai kayu leaves & $\begin{array}{l}\text { Morinda citrifolia leaves, Syzygium polyanthum } \\
\text { (Wight) Waplers leaves }\end{array}$ & Postnatal & $7(2)$ \\
\hline Kunyit, halia, serai & Curcuma longa, Zingiber officinale, Cymbopogon & $\begin{array}{l}\text { Postnatal, general health, skin } \\
\text { problems, menstrual problems }\end{array}$ & $7(2)$ \\
\hline Kucing galak leaves & Acalypha Indica leaves & Postnatal & $6(1)$ \\
\hline Halia bara, jenjulung roots, serapat roots & $\begin{array}{l}\text { Alpinia purpurata, Dracaena graminifolia roots, } \\
\text { Mapania cuspidate roots }\end{array}$ & $\begin{array}{l}\text { General health, skin problems, } \\
\text { endometriosis }\end{array}$ & $4(1)$ \\
\hline
\end{tabular}

Table 3 Perception Towards The Use Of Herbal Remedies Among Malay Women In Malaysia ( $n=1067)$

\begin{tabular}{|c|c|c|c|c|}
\hline \multirow[t]{2}{*}{ Safety And Efficacy Of The Herbal Remedies } & \multicolumn{2}{|l|}{ Yes } & \multicolumn{2}{|l|}{ No } \\
\hline & $n$ & $\%$ & n & $\%$ \\
\hline Herbal remedies are safer than modern drugs & 540 & 50.6 & 527 & 49.4 \\
\hline Herbal remedies are effective for managing health problems for women & 623 & 58.4 & 444 & 41.6 \\
\hline Herbal remedies should be used by all women & 446 & 41.8 & 621 & 58.2 \\
\hline Herbal remedies may cause problems to women's overall health & 342 & 32.1 & 725 & 67.9 \\
\hline All herbal remedies can safely be used during pregnancy & 88 & 8.2 & 979 & 91.8 \\
\hline I am satisfied with the effect and outcomes of using herbal medicines & 657 & 61.6 & 410 & 38.4 \\
\hline
\end{tabular}


all remedies were safe for pregnant women $(n=979$, $91.8 \%)(\chi 2=744.03, \mathrm{df}(1), \mathrm{p}<0.001)$.

A comparison was then performed between perceived safety of herbs with the use of herbal remedies among respondents. Respondents that admit to using herbs agreed that it was safer (herb user; $n=405,38 \%$ vs non-user: $n=187$, $17.5 \%)$ than modern medicines $(\chi 2=172.2, \mathrm{df}(1), \mathrm{p}<0.01)$ and effective (herb user; $n=462,43.3 \%$ vs non-user: $n=130$, $12.2 \%)$ in managing health $(\chi 2=215.2, \mathrm{df}(1), \mathrm{p}<0.01)$. Those that did use herbs also agreed that it should be used by all women (herb user; $n=353,33.1 \%$ vs non-user: $n=239$, $22.4 \%)(\chi 2=173.8, \mathrm{df}(1), \mathrm{p}<0.01)$ as it will not cause problems (herb user; $n=482,45.2 \%$ vs non-user: $n=110,10.3 \%$ ) $(\chi 2=109.4, \operatorname{df}(1), \mathrm{p}<0.01)$ as they were satisfied with the effects of herbal remedies (herb user; $n=535,50.1 \%$ vs non-user: $\mathrm{n}=57,5.3 \%)(\chi 2=458.3, \mathrm{df}(1), \mathrm{p}<0.01)$.

\section{Predictors Of Herbal Use Among Women}

A univariate and multivariate logistic regression analysis was performed to identify demographic characteristics that predicted the use of herbs for health (Table 4). Predictors from the univariate analysis with a p-value $<0.05$ were then included in the multivariate analysis. The multivariate logistic regression model was statistically significant $(\chi 2=203.98, \operatorname{df}(795) \mathrm{p}<0.001)$, and demonstrated that marital status and monthly income were significant predictors of herbal use for health when holding all other variables constant. Those that were married were 3.9 times more likely to use herbs than unmarried women $(\mathrm{p}<0.001)$.
Having an income of $<$ RM 3000 or USD 729 increased the odds of using herbs among women by 6.2 times compared to their counterparts $(\mathrm{p}<0.001)$. The model was able to explain $30.4 \%$ of the variance in the use of herbs for health and correctly identified $69.7 \%$ of the cases.

\section{Discussion}

Herbal remedies are popular in most cultures and are rightfully acknowledged by modern practitioners. ${ }^{16,24}$ Among women, the use of herbs for health issues is very common and despite the vast numbers of evidence-based modern medicine, it is still preferred. ${ }^{24}$ Not surprisingly, approximately half of the respondents admit to taking herbs for health in Malaysia, similar to previous work. ${ }^{24}$ The most common of these are in the form of raw plants or prepacked commercialized herbs, which are often taken orally. The increase in the utilization of herbs for medicinal purposes and general health is not only observed in Malaysia, but is common around the world. ${ }^{2}$ Therefore, it is essential to facilitate better understanding of its use among the public in order to furnish safe and effective use of herbal medicine.

The exploitation of herbs for medicinal purposes may differ depending on location, due to the variation in culture, indication, plant species availability and beliefs. ${ }^{11,25}$ Among these, Marantodes pumilum, Nigella sativa and Croton caudatus were among the most popular and preferred herbs, similar to previous reports., ${ }^{8,2,25}$ Although both Marantodes pumilum and Croton caudatus were mainly used for postnatal care, there are other common uses such as general health and skin problems. This is also

Table 4 Factors Affecting The Use Of Herbs For Health Among Malay Women In Malaysia $(n=1067)$

\begin{tabular}{|c|c|c|c|c|c|}
\hline & Beta & OR & Lower $95 \% \mathrm{Cl}$ & Upper $95 \% \mathrm{Cl}$ & p-value \\
\hline Demographics (Ref) & \multicolumn{5}{|c|}{ Univariate Logistic Regression } \\
\hline Age $(\geq 35)$ & 0.359 & 1.432 & 0.117 & 0.602 & 0.004 \\
\hline Education (Tertiary) & -0.237 & 0.789 & -0.525 & 0.05 & 0.105 \\
\hline Marital status (Married) & 1.133 & 3.105 & 0.857 & 1.409 & $<0.001$ \\
\hline Employment (Employed) & $0.57 \mid$ & 1.770 & 0.300 & 0.842 & $<0.001$ \\
\hline Monthly income ( $\geq$ RM3000/USD729) & -1.828 & 0.161 & -2.158 & -1.499 & $<0.001$ \\
\hline Health status (Healthy) & -0.809 & 0.445 & -1.263 & -0.355 & $<0.001$ \\
\hline Demographics & \multicolumn{5}{|c|}{ Multivariate Logistic Regression } \\
\hline Age $(\geq 35)$ & 0.139 & 1.149 & -0.199 & 0.476 & 0.421 \\
\hline Marital status (Married) & 1.376 & 3.958 & 1.011 & $\mathrm{I} .74 \mathrm{I}$ & $<0.001$ \\
\hline Employment (Employed) & -0.045 & 0.956 & -0.787 & 0.697 & 0.905 \\
\hline Monthly income ( $\geq$ RM3000/USD729) & -1.822 & 0.162 & -2.173 & $-1.47 \mid$ & $<0.001$ \\
\hline Health status (Healthy) & -0.254 & 0.776 & -0.817 & 0.309 & 0.377 \\
\hline
\end{tabular}


apparent from previous work that details out other indications of Marantodes pumilum and Croton caudatus, which were to relieve muscle and body ache, promote baby's physical health and intelligence, prevent retained placenta and abortion purposes. ${ }^{11}$ It is thus not uncommon for Malay women to use a herbal remedy for multiple purposes, which further underscores the need to educate them on the safe use of herbal medicines.

Understanding the perception of herbal use is vital in view of public health issues, and concerns surrounding its safety. Although some herbal medicines have potential in treating illnesses and are widely used, many of them remain untested. ${ }^{2}$ Furthermore, the widespread use of herbal remedies is frequently unmonitored. This makes knowledge of potential adverse effects and drug interaction especially when used with modern medicines limited, and promotion of their rational use much more difficult. ${ }^{9}$ This becomes even more of a challenge when most women perceive that herbal use is much safer and effective than modern medicines, as observed in the current work. The general perception that herbal remedies are safe and devoid of adverse effects is untrue and misleading. ${ }^{10,14,15}$ It is therefore essential to equip the general public with adequate information on the appropriate use of herbal remedies in an attempt to facilitate a better understanding of the potential risks associated with herbs.

In the current work, married Malay women, with a monthly income of less than RM 3000 or USD 729 were predictors of herbal use. The popular use of herbs for postnatal care among married Malay women within the current work as well as previous studies ${ }^{8,11,12}$ further supports these findings. The accessibility and affordability of herbal remedies ${ }^{1,2}$ could possibly explain the link between lowerincome groups and use of herbs. Raw herbs are generously found in Malaysia and as such, are very much cheaper than conventional medicines. ${ }^{1,2}$ In addition to this, there is a growing culture of herbal agents and distributors within Malaysia, which makes purchasing these products much easier. The ease in obtaining herbs for medicinal use strengthens the need to identify herbal users among Malay women as it may aid healthcare professionals in designing educational programs and activities to reduce unwarranted adverse effects within this population.

As such, the aim of the study was successfully achieved. Despite this, there are a few limitations that should be addressed. As with all questionnaire-based studies, the findings of this study are dependent on the honesty of the respondents. It should also be noted that some herbal users may not be fully aware of the categories of herbal remedies. Due to the nature of raw plants or herbs being used, some may categorize the use as nutritional supplements despite using them for medicinal purposes. ${ }^{22}$ Furthermore, factors that affect herbal are not limited to those studied, and could also include other predictors such as ineffective use of modern medicine, belief, religion, knowledge and attitude towards herbs used. ${ }^{15,17}$

To that end, findings from this study suggest a need to focus our attention on providing appropriate programs on herbal medicine, especially among married women of lower-income groups. Despite the popularity of herbal remedies for well-being and health, herbs are capable of producing a wide range of undesirable effects if used too often. Some of these are capable of causing serious injuries and life-threatening conditions. ${ }^{26}$ Unfortunately to this day, healthcare professionals have a limited understanding of the potential effects of herbs. The current work also highlights the challenges associated with herbal education, due to the positive perception of herbal use among the study population. Furthermore, due to the common lack of disclosure of herbal use among women, ${ }^{16}$ healthcare providers should have an open and non-judgemental conversation with women about the use of herbal remedies to ensure safe and optimum management is achieved. Therefore, health educational programs on herbal use should be developed that address these concerns to ensure appropriate information is delivered.

\section{Acknowledgement}

The authors would like to thank all respondents that participated in the study.

\section{Author Contributions}

All authors contributed to the study design, data analysis, drafting and revising the article, gave final approval of the version to be published, and agree to be accountable for all aspects of the work.

\section{Disclosure}

The authors report no conflicts of interest in this work.

\section{References}

1. Islahudin F, Shahdan IA, Mohamad-Samuri S. Association between belief and attitude toward preference of complementary alternative medicine use. Patient Prefer Adherence. 2017;11:913-918.

2. Chintamunnee V, Mahomoodally MF. Herbal medicine commonly used against infectious diseases in the tropical island of Mauritius. $J$ Herb Med. 2012;2:113-125. 
3. Hussan F, Yahaya MF, Teoh SL, Das S. Herbs for effective treatment of diabetes mellitus wounds: medicinal chemistry and future therapeutic options. Mini-Rev Med Chem. 2018;18(8):697-710.

4. Hussain Z, Thu HE, Shuid AN, Kesharwani P, Khan S, Hussain F. Phytotherapeutic potential of natural herbal medicines for the treatment of mild-to-severe atopic dermatitis: A review of human clinical studies. Biomed Pharmacother. 2017;93:596-608.

5. Othman A, Nasir A, Mohammad N, Taib F. The use of Malay traditional healers in childhood cancer. Malaysian J Paediatr Child Health. 2016;20:26-37.

6. Aziz Z, Tey NP. Herbal medicines: prevalence and predictors of use among Malaysian adults. Complement Ther Med. 2009;17 (1):44-50.

7. Sooi LK, Keng SL. Herbal medicines: Malaysian women's knowledge and practice. Evid-Based Complementary Altern Med. 2013; 2013:438139. Available from: https://www.hindawi.com/journals/ ecam/2013/438139/cta. Accessed July 21, 2018.

8. Ramli MR, Millow P, Chooi OH. Traditional knowledge of a practitioner in medicinal plants of Masjid Ijok Village, Perak, Malaysia. Stud Ethno-Med. 2015;9(1):59-66.

9. Yusof J, Mahdy ZA, Noor RM. Use of complementary and alternative medicine in pregnancy and its impact on obstetric outcome. Complement Ther Clin Pract. 2016;25:155-163.

10. Aziz NA, Ahmad MI, Naim DM. Molecular DNA identification of medicinal plants used by traditional healers in Malaysia. Genet Mol Res. 2015;14(4):15937-15947.

11. Rahman AA, Sulaiman SA, Ahmad Z, Daud WN, Hamid AM. Prevalence and pattern of use of herbal medicines during pregnancy in Tumpat district, Kelantan. Malays J Med Sci. 2008;15(3):40.

12. Ong HC, Zuki RM, Milow P. Traditional knowledge of medicinal plants among the Malay villagers in Kampung Mak Kemas, Terengganu, Malaysia. Stud Ethno-Med. 2011;5(3):175-185.

13. Golian TS, Mirmohammadali M, Mehran A, Taghizadea M, Baleghi M. The comparison of fennel and mefenamic acid effects on postpartum after pain. J Babol Univ Med Sci. 2015;17(8):7-13.

14. Haslan H, Suhaimi FH, Das S. Herbal supplements and hepatotoxicity: a short review. Nat Prod Commun. 2015;10(10):1779-1784. $1934578 X 1501001035$.
15. Olowekere AE, Olajide O. Women's perception of safety and utilization of herbal remedies during pregnancy in a local government area in Nigeria. Clin Nurs Stud. 2013;1(4):9-22.

16. Frawley J, Adams J, Steel A, Broom A, Gallois C, Sibbritt D. Women's use and self-prescription of herbal medicine during pregnancy: an examination of 1,835 pregnant women. Women's Health Issues. 2015;25(4):396-402.

17. Foo JU, Latiff A, Omar MU, Amir AA. Women's perception on medicinal plants in traditional Tamu, West Coast, Sabah, Malaysia. Malay Nat J. 2016;68(3):95-104.

18. Krejcie RV, Morgan DW. Determining sample size for research activities. . Educ Psychol Meas. 1970;30(3):607-610.

19. Department of Statistics Malaysia. Current population estimates Malaysia 192017-2018. 2019. Available from: https://www.dosm.gov.my/v1/ index.php?r=column/cthemeByCat\&cat=155\&bul id= aWJZRkJ4UEdKcUZpT2tVT090Snpydz09\&menu_id= L0pheU43NWJwRWVSZklWdzQ4TlhUUT09. Accessed June 24, 2019

20. Regmi PR, Waithaka E, Paudyal A, Simkhada P, van Teijlingen E. Guide to the design and application of online questionnaire surveys. Nepal J Epidemiol. 2016;6(4):640-644.

21. Suleiman AK. Attitudes and beliefs of consumers of herbal medicines in Riyadh, Saudi Arabia. J Community Med Health Educ. 2014;4:269.

22. National Institutes of Health. Office of dietary supplements. Botanical dietary supplements: background information. 2011. [updated June 24, 2011]. Available from: http://ods.od.nih.gov/fact sheets/botanicalbackground.asp. Accessed January 15, 2016.

23. Li T, Sheng J, Li W, et al. A new computational model for human thyroid cancer enhances the preoperative diagnostic efficacy. Oncotarget. 2015;6(29):28463.

24. Aagaard SK, Larsen A, Andreasen MF, Uldbjerg N, Bor P. Use of complementary and herbal medicine in the general population and among pregnant women. Ugeskr Laeger. 2017;179(5):

25. Jamal JA, Ghafar ZA, Husain K. Medicinal plants used for postnatal care in Malay traditional medicine in the Peninsular Malaysia. Pharmacogn Rev. 2011;3(24):15-24.

26. Lee JY, Jun SA, Hong SS, Ahn YC, Lee DS, Son CG. Systematic review of adverse effects from herbal drugs reported in randomized controlled trials. Phytother Res. 2016;30(9):1412-1419.
Patient Preference and Adherence

\section{Publish your work in this journal}

Patient Preference and Adherence is an international, peer-reviewed, open access journal that focusing on the growing importance of patient preference and adherence throughout the therapeutic continuum. Patient satisfaction, acceptability, quality of life, compliance, persistence and their role in developing new therapeutic modalities and compounds to optimize clinical outcomes for existing disease states are major areas of interest for the journal. This journal has been accepted for indexing on PubMed Central. The manuscript management system is completely online and includes a very quick and fair peer-review system, which is all easy to use. Visit http:// www.dovepress.com/testimonials.php to read real quotes from published authors. 